\title{
Effects of Glutamine on Healing of Traumatic Oral Mucosal Lesions: An Experimental Study
}

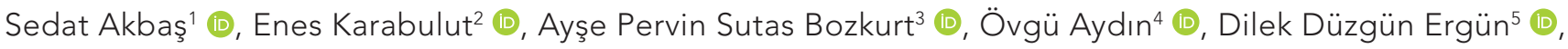 \\ Gürcan Güngör ${ }^{3}$ (B) \\ 1Department of Anesthesiology and Reanimation, Inönü University School of Medicine, Malatya, Turkey \\ 2Department of Clinical Trials, Turkish Medicines and Medical Devices Agency, Ankara, Turkey \\ ${ }^{3}$ Department of Anesthesiology and Reanimation, İstanbul University-Cerrahpaşa, Cerrahpaşa School of Medicine, İstanbul, Turkey \\ ${ }^{4}$ Department of Pathology, İstanbul University-Cerrahpaşa, Cerrahpaşa School of Medicine, ìstanbul, Turkey \\ ${ }^{5}$ Department of Biophyshics, İstanbul University-Cerrahpaşa, Cerrahpaşa School of Medicine, İstanbul, Turkey
}

Cite this article as: Akbaş S, Karabulut E, Sutas Bozkurt AP, Aydın Ö, Düzgün Ergün D, Güngör G. Effects of Glutamine on Healing of Traumatic Oral Mucosal Lesions: An Experimental Study. JAREM 2019; 9(1): 6-13.

\begin{abstract}
Objective: Glutamine (GLN) plays an important role in the regulation of acid-base balance, protein turnover, ammonia metabolism, catabolic situations, and immune system enhancement. The prevention, treatment, and care of oral mucosal lesions are very important in terms of leading to several clinical and economic problems. The aim of the present study was to investigate the positive and different effects of GLN on traumatic oral mucosal lesions by its administration via the topical or systemic (enteral and parenteral) route.

Methods: Twenty-one Wistar albino rats were included in the experimental study and divided into four groups. Traumatic oral mucosal lesions were created in all rats after the intraperitoneal administration of anesthesia. In the control group, traumatic oral mucosal lesions were created and no treatment was applied. In the study groups, GLN was applied via the parenteral, enteral, and topical routes. Healing of lesions was macroscopically observed on high-resolution photographs. Rats were sacrificed, and biopsies were obtained for histopathological and biochemical evaluations.

Results: In histopathological evaluations of the biopsies, a significant difference was observed between the control and parenteral/topical groups for acute inflammation, between the control and parenteral groups for epithelial proliferation, and between the control and topical groups for fibrosis. In biochemical evaluations, only malondialdehyde levels had a significant difference between the control and enteral groups $(p<0.02)$.

Conclusion: A positive effect of GLN administration was observed for the treatment of traumatic oral mucosal lesions. It was considered that GLN administration via the topical or enteral route may present an alternative on traumatic oral mucosal lesions. However, GLN administration via the parenteral route had better results than that via topical and enteral routes.
\end{abstract}

Keywords: Experimental study, glutamine, oral mucositis, traumatic wounds

\section{INTRODUCTION}

Oral lesions are defined as the inflammation of oral mucosa, compromised by damage of the epithelial tissue with the impairment of the saliva barrier, damage of the epithelial cells, and frequent ulcerations (1). Oral mucosal cells, along with secreted substances, constitute the first line of defense. The lesions cause opportunistic oral infections by inflicting mucosal damage and fatal complications, such as bacteremia, fungemia, and sepsis (1). The lesions, which lead to severe pain, are the main cause of difficulties related to chewing, swallowing, and speaking, which then contribute to dehydration, malnutrition, anorexia, and cachexia (1).

The major risk factors for oral mucositis are age, sex, genetic factors, lack of oral hygiene, xerostomia, nutrition status, acute or chronic dental diseases, infections, malignancies, smoking, alcohol, presence and severity of instrumentation inside the mouth, chemotherapy and radiotherapy, and treatment-related causes (2). The treatment of oral mucositis includes options of nutritional support, pain management, oral hygiene, and palliation of xerostomia. Requirement for total parenteral nutrition and treatment of infections, long duration of febrile neutropenia, using higher doses of opioid analgesics for oral mucositis lead to a prolonged hospitalization period, thereby increasing treatment costs.

Amino acids and vitamins are used to support the immune system (3). Glutamine (GLN) has an important role in the synthesis of nucleotides in rapidly dividing cells (4). GLN, which plays a crucial role in wound healing, is not present in sufficient quantities in enteral and total parenteral nutrition because of solubility and 
stability problems, although it is the most abundant amino acid in the blood (4). Nutritional support with GLN plays a significant role in terms of shortening the hospitalization period, reducing treatment costs, and providing quality life standards to patients (1).

In our clinical experience, patients with oral mucositis due to trauma or diseases healed faster when nutritional support with GLN was provided. Therefore, this study aimed to investigate the positive and different effects of GLN on traumatic oral mucosal lesions by its administration via the topical or systemic (enteral and parenteral) route.

\section{METHODS}

Study Protocol: This experimental study was approved by the Animal Experiments Local Ethics Committee and conducted at the Animal Experiments Laboratory of Cerrahpaşa School of Medicine. The study was conducted in accordance with the guideline for the use and care of laboratory animals.

Animal Preparation: The study was conducted on 21 Wistar albino-type male rats weighing between 250 and 350 g. Care for experimental animals was provided in four rat cages (Euro type 3 , polycarbonate stainless steel cage, $150-\mathrm{mm}$ height, $375 \times 215$ $\mathrm{mm}$ bottom edges, and $425 \times 265-\mathrm{mm}$ roof edge) where rat chow and water were provided without any restriction in the diet at a room temperature of $21^{\circ} \mathrm{C}-22^{\circ} \mathrm{C}$ with a 12 -hour day/12-hour night period with three or six rats in the same cage before and during the study.

Experimental Protocol: All experiments were performed under anesthesia and analgesia with $75 \mathrm{mg} / \mathrm{kg}$ ketamine hydrochloride $\left(\operatorname{Ketalar}^{\circledR}\right)$ and $5 \mathrm{mg} / \mathrm{kg}$ xylazine (Rompun $\left.{ }^{\circledR}\right)$. The weight of animals, drugs, and dosages are presented in Table 1. The left buccal mucosa inside the mouth was reached using a small retractor with a hook to the upper and lower jaw teeth without damaging the structure of the mouth and jaw and exposing any additional trauma. In the left buccal mucosa of the oral cavity, traumatic mucosal lesion was formed as a plus (+) by a needle $(12 \times 12 \mathrm{~mm})$. The lesions created in all experiments were photographed from a distance of 3-5 $\mathrm{cm}$ to demonstrate a standard damage form (Figure 1). Anesthesia and analgesia were administered to all study groups (parenteral, enteral, and topical) for 5 days before each drug administration.

All experiments were allocated to four groups as control (C), parenteral $(P)$, enteral $(E)$, and topical $(L)$. In group $C(n=3)$, the lesions were created and no treatment was applied. In group $P$ $(n=6), G L N\left(\right.$ Dipeptiven ${ }^{\circledR}$, Fresenius Kabi) at a dose of $0.4 \mathrm{mg} \mathrm{kg}^{-1}$ day $^{-1}$ was slowly injected to the tail vein using an insulin needle.
In group $E(n=6)$, the feeding tube (no. 6, $10 \mathrm{~cm}$ ) was pushed forward from the mouth to the stomach, and GLN (Resource Glutamin ${ }^{\circledR}$, Nestle) at a dose of $1 \mathrm{~g} / \mathrm{kg} /$ day was administered without contact to the oral mucosa. In group L $(n=6)$, GLN (Resource Glutamin ${ }^{\circledR}$, Nestle) at a dose of $1 \mathrm{~g} / \mathrm{kg} /$ day was administered by applying the ear bar to the lesion. Drug administration was performed in all study groups by repeating the procedure for 5 days twice a day at the same time. The experimental design is presented in Table 2.

Macroscopic Evaluation: After the lesions were created, they were photographed using a high-resolution machine before the drug administration during 5 days. The healing process of the lesions was macroscopically observed with respect to the presence of redness, edema, bleeding, and scar tissue.

Obtaining Tissue Samples: Euthanasia was performed after 5 days once the lesion had been created by intraperitoneally injecting ketamine $200 \mathrm{mg} / \mathrm{kg}\left(\right.$ Ketalar $\left.^{\circledR}\right)$ and thiopental sodium $150 \mathrm{mg} / \mathrm{kg}$ (Pental $\left.{ }^{\circledR}\right)$. Scar tissue was dissected and divided into two samples-one of the samples was stored for histopathological evaluation and the other one was used for the analysis of oxidative stress factors.

Histopathological Evaluation: Biopsy specimens were embedded in paraffin, cut, and stained with hematoxylin and eosin after 48h of formalin fixation. These specimens were analyzed by a pathologist blinded to the experimental study. First, cross-sections were scanned, and then areas of pathological changes were characterized. Epithelial proliferation, acute inflammation, vascular proliferation, and fibrosis that are important for wound healing were evaluated based on the pathological scoring criteria generated by a pathologist. The modified and updated form of the Shafer histopathological scoring criteria (5) for all parameters was assessed on two scores based on intensity and diffuseness of the cells (score 1: nothing to appear or $<10 \%$ on section, score $2: \geq 10 \%$ on section).

Biochemical Analysis: Tissue samples obtained for biochemical analysis were exposed to spectrophotometric measurements using the supernatant Elisa method with a 450-nm wavelength. An Easybiofarm (China) commercial kit was used for malondialdehyde (MDA, lipid peroxidation product), superoxide dismutase (SOD, antioxidant), glutathione peroxidase (GSH-Px, enzymes of antioxidant defense system), and hydroxyproline (HYP) measurements.

\section{Statistical Analysis}

Histopathological and biochemical evaluation results were evaluated using the Statistical Package for Social Sciences version 9.0 (SPSS Inc.; Chicago, IL, ABD) Fisher's exact test, Chi-square test, and Mann-Whitney $U$ test were used to compare binary histo-

Table 1. Weight of animals, drugs, and dosages

\begin{tabular}{|c|c|c|c|c|}
\hline & $\begin{array}{l}\text { Control group } \\
(n=3) \text { Mean } \pm S D\end{array}$ & $\begin{array}{l}\text { Parenteral group } \\
(n=6) \text { Mean } \pm S D\end{array}$ & $\begin{array}{l}\text { Enteral group } \\
(n=6) \text { Mean } \pm S D\end{array}$ & $\begin{array}{l}\text { Topical group } \\
(n=6) \text { Mean } \pm S D\end{array}$ \\
\hline Weight (mg) & $292.0 \pm 10.58$ & $303.3 \pm 12.69$ & $289.2 \pm 18.03$ & $297.0 \pm 18.54$ \\
\hline Xylazine (Rompun $\left.{ }^{\circledR}\right)$ (mg) & $1.46 \pm 0.05$ & $1.48 \pm 0.07$ & $1.43 \pm 0.08$ & $1.43 \pm 0.10$ \\
\hline
\end{tabular}




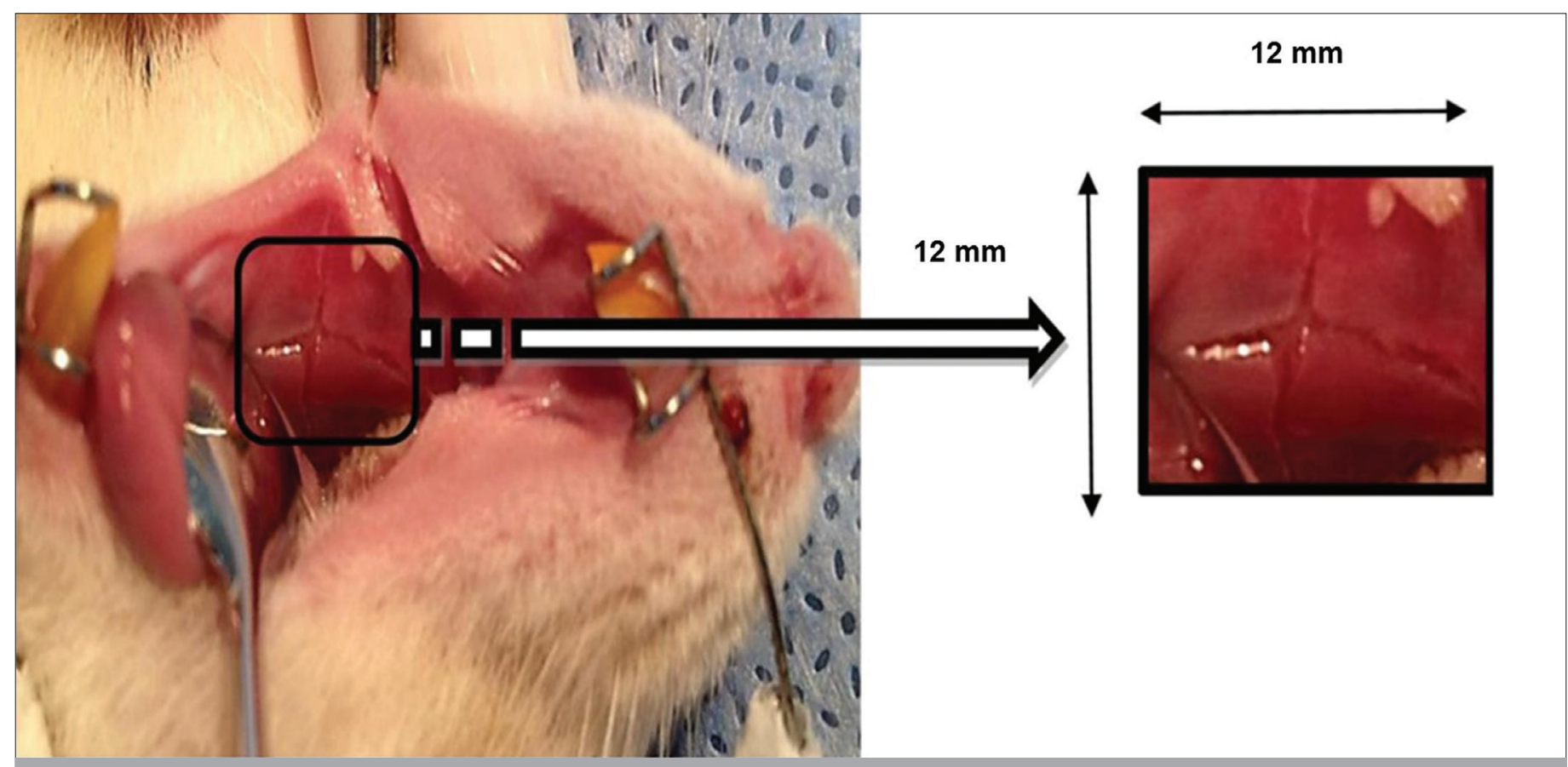

Figure 1. Making oral mucosal lesion

Table 2. Experimental design

\begin{tabular}{|c|c|}
\hline Groups & No. of animals \\
\hline \multicolumn{2}{|l|}{ Group C: control group } \\
\hline $\begin{array}{l}\text { Making purely traumatic oral } \\
\text { mucosal lesion }\end{array}$ & 3 \\
\hline \multicolumn{2}{|l|}{ Group P: parenteral group } \\
\hline $\begin{array}{l}\text { Administered by parenteral GLN1 } \\
(0.4 \mathrm{mg} / \mathrm{kg} / \text { day })\end{array}$ & 6 \\
\hline \multicolumn{2}{|l|}{ Group E: enteral group } \\
\hline $\begin{array}{l}\text { Administered by (feeding tube) } \\
\text { enteral GLN ( } 1 \mathrm{~g} / \mathrm{kg} / \text { day) }\end{array}$ & 6 \\
\hline \multicolumn{2}{|l|}{ Group T: topical group } \\
\hline $\begin{array}{l}\text { Administered by (ear bar) topical } \\
\text { GLN (1 g/kg/day) }\end{array}$ & 6 \\
\hline GLN: glutamine & \\
\hline
\end{tabular}

pathological evaluation parameters between the groups. $p<0.05$ was considered statistically significant in resulted values. For biochemical evaluation parameters, differences among groups were analyzed using Kruskal-Wallis test, and Mann-Whitney $U$ test with a Bonferroni correction was used for pairwise comparisons. $p<0.02$ was considered statistically significant in resulted values.

\section{RESULTS}

Macroscopic Findings: The control group had redness, edema, and bleeding at 48-72h and scar tissue at days 4 and 5 . The parenteral group had redness, less edema, and bleeding at 24-36h and scar tissue at days 3 and 5 . The enteral group had redness, edema, and bleeding at 24-48h and scar tissue at days 3 and 5 .
The topical group had redness and edema at 24-48h and scar tissue at days 3 and 5 .

Histopathological Findings: There was a significant difference between the control and parenteral groups in terms of epithelial proliferation ( $p=0.012$ ) (Figure 2); between the control, parenteral, and enteral groups in terms of acute inflammation $(p=0.018)$ (Figure 3); and between the control and topical groups in terms of fibrosis ( $p=0.029$ ) (Figure 4). Histopathological evaluation is presented in Table 3.

Oxidative Stress Analysis: There was no significant difference between the groups in SOD, GSH-Px, and HYP levels. In terms of MDA values, there was a significant difference between the control and enteral groups $(p<0.02$ and $p<0.02$, Figure 5). Oxidative stress analysis of MDA, SOD, GSH-Px, and HYP is presented in Table 4.

\section{DISCUSSION}

In this experimental animal model, the effects of GLN administration via the topical or systemic (enteral and parenteral) route in the treatment of traumatic oral mucosal lesions were demonstrated. The healing process of the lesions lasting days, months, or even years is a dynamic process. GLN appears to be more effective in the initial 3-5 days in which it has a turnover time of mucosal cells after mucosal damage (6).

A normal wound healing process comprises the inflammatory and proliferative phases, maturation, and remodeling. Several topical and systemic agents were used for shortening the process and studied to accelerate the wound healing process (7). In normal wound healing, evaluation of the interaction between clinical, cellular, and other factors plays an important role in the planning and development of convenient therapeutic methods (8). In the macroscopic evaluation in our study, the control group had redness, edema, and bleeding on day 3 and 


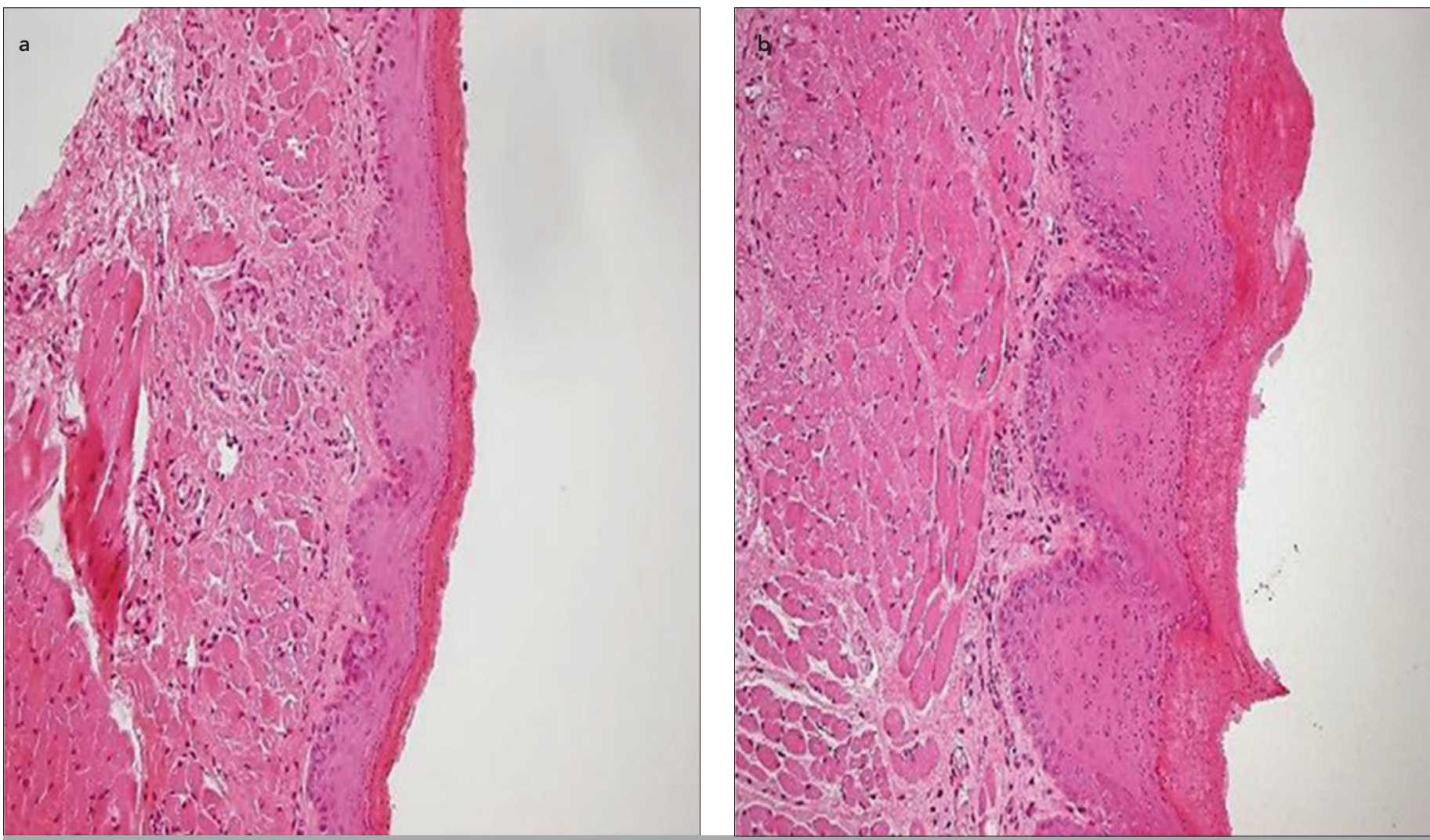

Figure 2. a, b. Epithelial proliferation (a) control group and (b) parenteral group
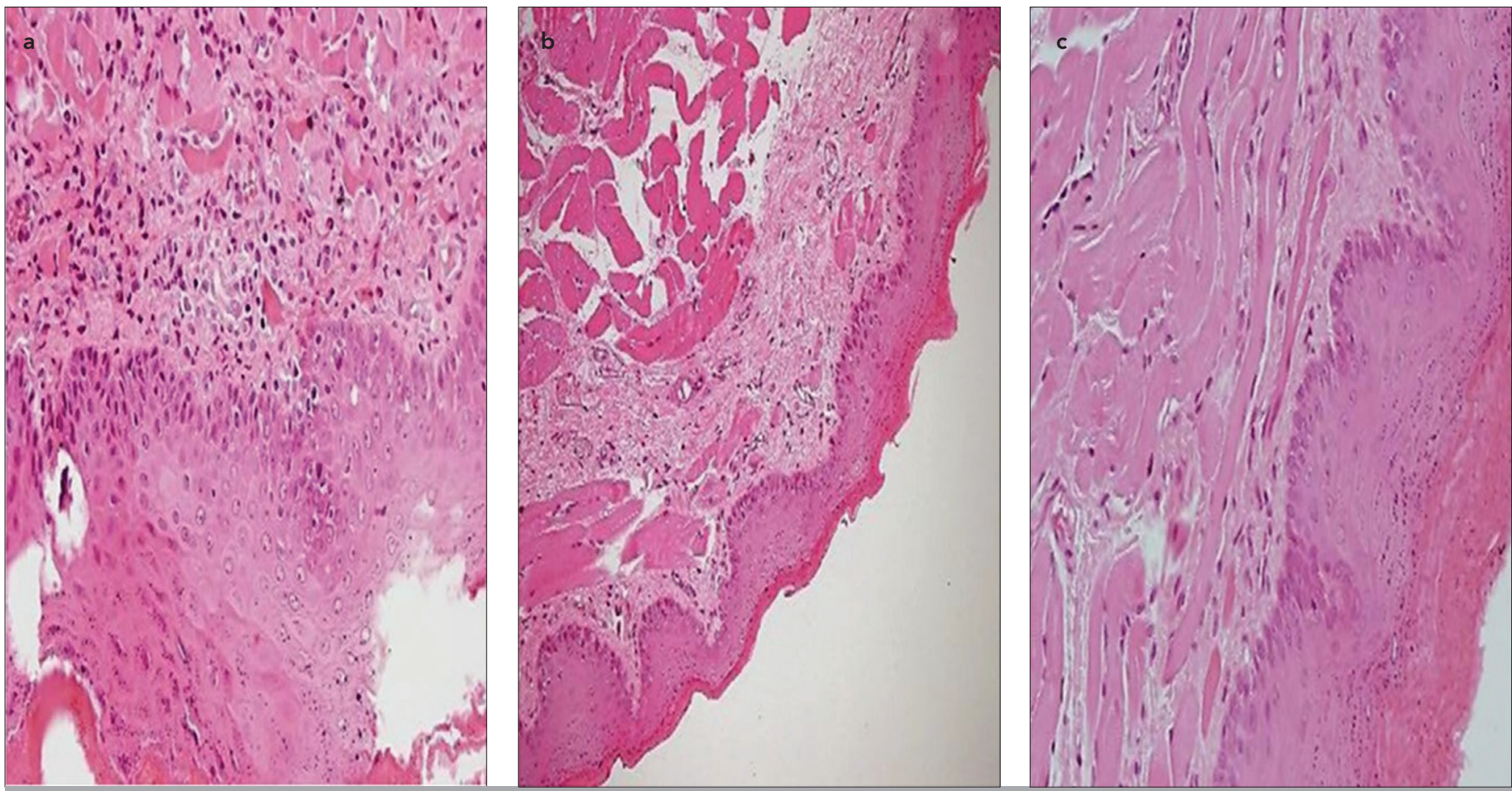

Figure 3. a-c. Acute inflammation (a) control group (b) parenteral group, and (c) enteral group

scar tissue on days 4 and 5 after creating the lesions. However, the study groups had redness, edema, and bleeding on day 2 and less extent of scar tissue. Further, there was a significant difference between the control and parenteral groups in terms of epithelial proliferation ( $p=0.012$ ). A positive effect of GLN on epithelial proliferation was observed; however, there was 

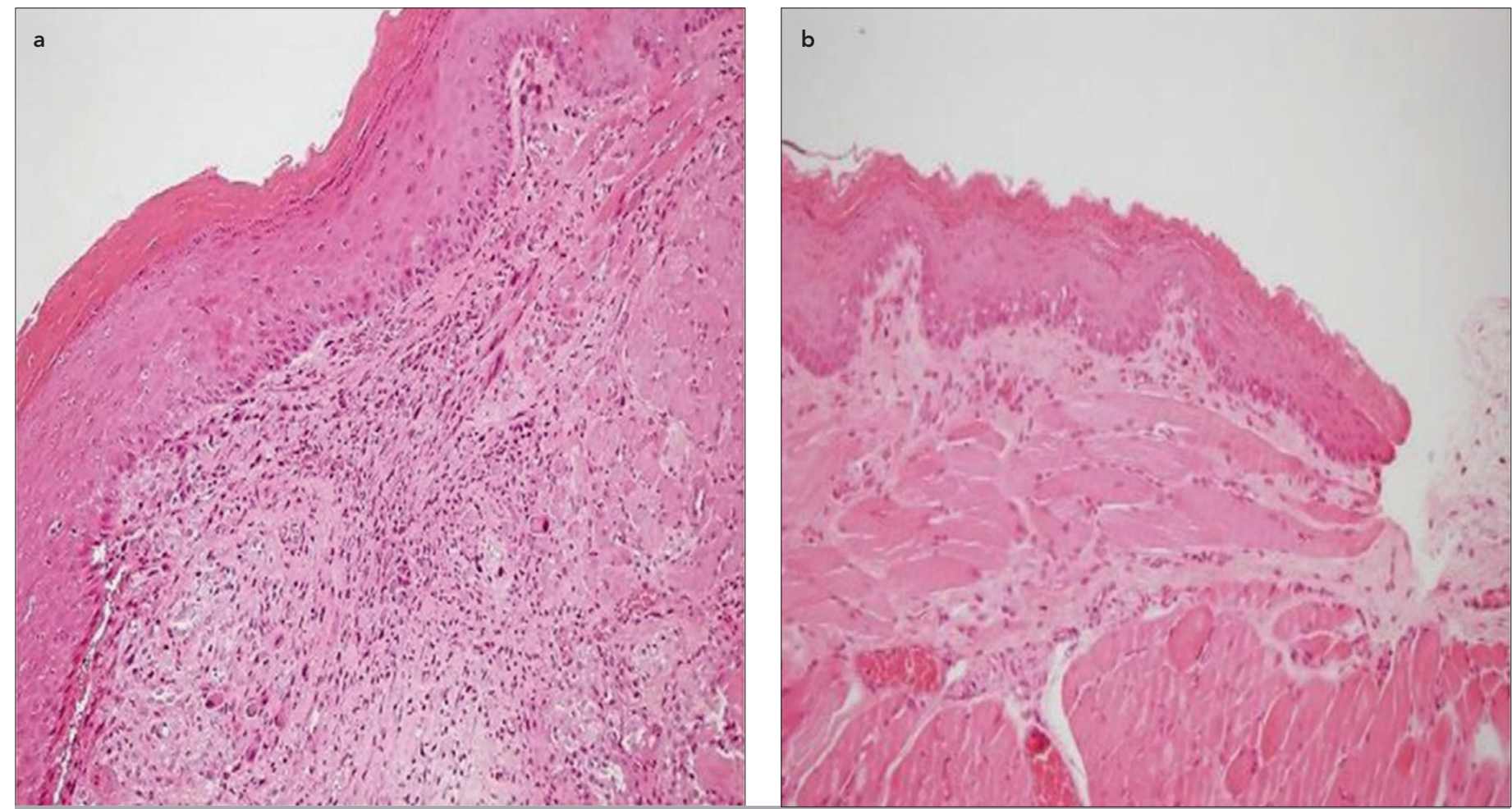

Figure 4. a, b. Fibrosis (a) control group and (b) topical group

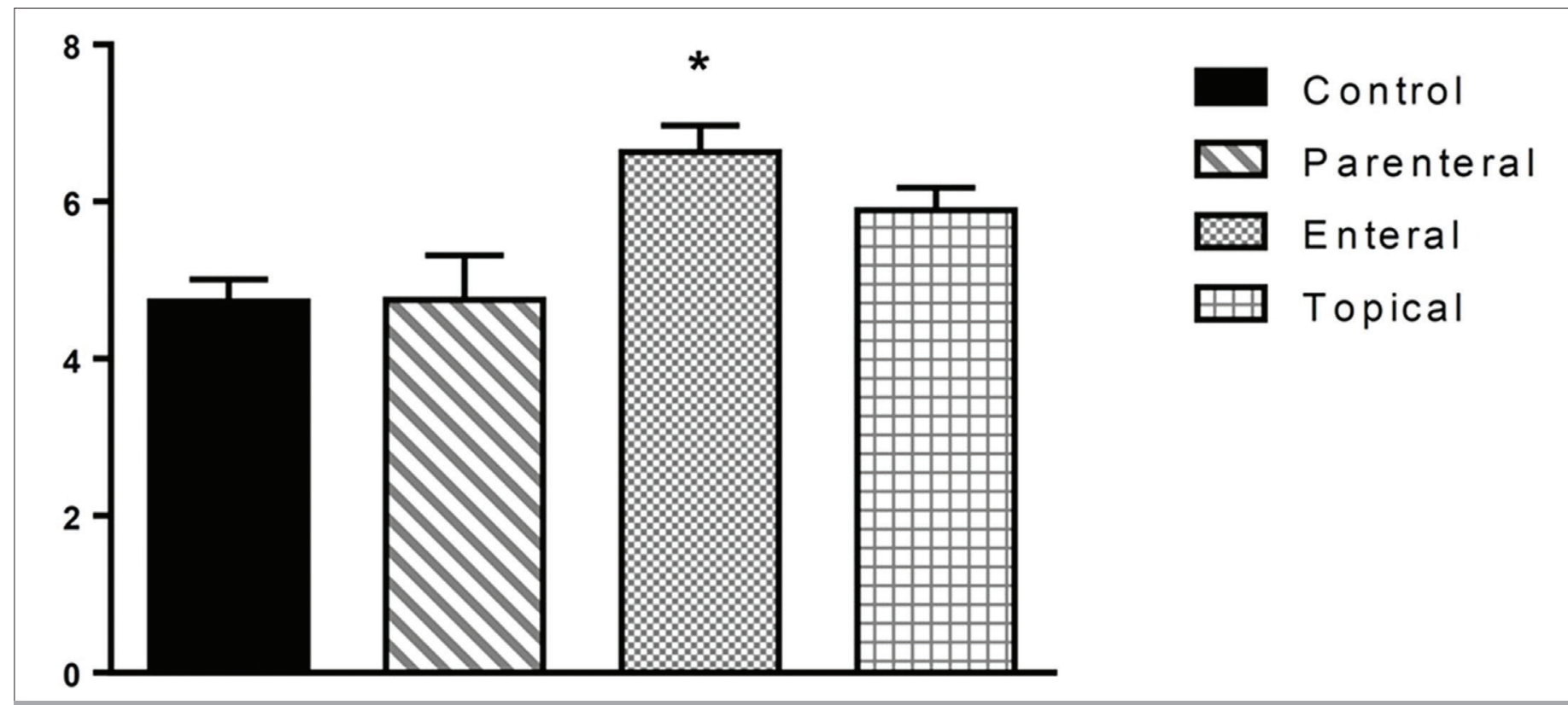

Figure 5. MDA levels, mean value, and standard deviation (StdD). *Significant difference between the control and enteral groups

no significant difference between the control and other study groups. Also, there was no significant difference between the study groups. The results of the enteral and topical groups were similar, although the best results in the study groups were observed in the parenteral group. Previous studies have shown that the enteral administration of GLN instead of parenteral administration reduces mucosal atrophy, bacterial translocation, and the incidence of sepsis (9).
Glutamine (GLN) administration via the enteral route is more effective than that via the parenteral route that has limited effects on intestinal cells (10). However, in our study, parenteral results had a better healing process. Muscle and plasma GLN levels are reduced during the period of catabolic stress. GLN is an important energy source for continuity, maintenance, and repair of gastrointestinal mucosa and for reducing intestinal mucosal injury. Inflammation is a response that occurs against tissue damage caused by infections and physical or chemical agents 
Table 3. Histopathological evaluation

\begin{tabular}{|c|c|c|c|c|c|}
\hline & 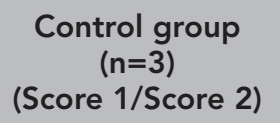 & $\begin{array}{l}\text { Parenteral group } \\
\qquad(n=6) \\
\text { (Score } 1 / \text { Score 2) }\end{array}$ & $\begin{array}{l}\text { Enteral group } \\
\qquad(n=6) \\
\text { (Score 1/Score 2) }\end{array}$ & $\begin{array}{c}\text { Topical group } \\
(n=6) \\
\text { (Score 1/Score 2) }\end{array}$ & $p$ \\
\hline Acute inflammation, $\mathrm{n}$ & $0 / 3^{\star *}$ & $6 / 0 * \star$ & $5 / 1 *$ & $3 / 3$ & $0.018^{\star \star}$ \\
\hline Vascular proliferation, $\mathrm{n}$ & $1 / 2$ & $0 / 6$ & $0 / 6$ & $1 / 5$ & 0.486 \\
\hline
\end{tabular}

Table 4. Oxidative stress analysis of MDA, SOD, GSH-Px, and HYP

\begin{tabular}{|c|c|c|c|c|}
\hline & MDA (ng/mL) & SOD (ng/mL) & GSH-Px (ng/mL) & HYP (ng/mL) \\
\hline Mean $\pm \mathrm{SD}^{5}$ & $4.72 \pm 0.49$ & $0.22 \pm 0.22$ & $106.00 \pm 83.62$ & $811.66 \pm 110.71$ \\
\hline \multicolumn{5}{|c|}{ Parenteral group $(n=6)$} \\
\hline Mean $\pm S D$ & $4.75 \pm 1.37$ & $1.34 \pm 1.71$ & $108.00 \pm 11.41$ & $1063.16 \pm 274.08$ \\
\hline \multicolumn{5}{|c|}{ Enteral group $(n=6)$} \\
\hline Mean $\pm S D$ & $6.63 \pm 0.82$ & $1.31 \pm 1.23$ & $89.66 \pm 44.41$ & $837.16 \pm 231.41$ \\
\hline \multicolumn{5}{|c|}{ Topical group $(n=6)$} \\
\hline Mean \pm SD & $5.97 \pm 0.64$ & $3.46 \pm 3.27$ & $93.16 \pm 26.50$ & $765.83 \pm 286.15$ \\
\hline
\end{tabular}

in organisms. Erbil et al. (11) reported that GLN has benefits for the inflammation process of intestinal cells. In our study, acute inflammatory cells were more widespread and intense in the control group than in the study groups. A presence of acute inflammatory cells for a longer time was considered to be cleaned in a longer time. Contrary to our expectations, acute inflammatory cells were located for a longer time and more intensive when the topical group compared to parenteral and enteral group. Therefore, wound healing was observed starting later. Topical GLN was not the reason behind the shortened time of acute inflammation. Thus, the difference between the enteral and topical groups was the slight inevitable trauma on the mucous layer in topical application, making acute inflammation to persist. A better result in the parenteral group was considered because the optimal level without plasma GLN had been exposed to presystemic elimination. It was considered that the optimal plasma GLN level was reached via the systemic route similar to the enteral route just after topical application because of the swallowing reflex.

Enteral supplementation cannot be routinely used because of the instability of GLN solution. Topical GLN provides the growth of gastrointestinal cells, preventing evolving intestinal atrophy in total parenteral nutrition patients (12). Topical GLN would be useful for enhancing mucosal contact. However, in our study, the same result was not obtained. Skubitz et al. reported that topicaloral GLN after chemotherapy reduces the grade and duration of mucositis. Similarly, Anderson et al. (13) reported that topical-oral
GLN reduces the grade of oral mucositis and decreases oral pain as soon as 4-5 days.

Revascularization in the wound healing process is very important in terms of nutrition of the damaged tissue area. In our study, there was no significant difference between the control and study groups in terms of vascular proliferation. Although it was expected that it would be better for vascular proliferation for topical GLN, there was no difference compared with the study groups.

A normal wound healing process does not always have an expected conclusion. It may result as a scar tissue development and failure to catch up with old properties of the healed area. It is important in clinical practice that wound healing resulted in shorter time and less sequelae. In our study, there was a significant difference among the control and topical groups in terms of fibrosis $(p=0.029)$. The control group had widespread and intensive fibrosis, whereas the topical group had less grade of fibrosis. Thus, GLN allowed re-epithelialization by delaying or preventing fibrosis. San-Miguel et al. reported that GLN significantly prevents the occurrence of intensive fibrosis in studies on the effects of antifibrinogen (14).

Wound healing is a pathophysiological process that includes cellular interaction and biochemical events. Reactive oxygen species in cells is continuously produced during normal metabolism, and the cells protect themselves from the damage of products by antioxidant mechanisms. However, the tissues face oxidative 
damage if that balance is corrupted (15). Increasing SOD and MDA levels is claimed in the presence of oxidative stress. The increase of SOD activity demonstrates the capacity of cellular antioxidant activity, and the increase of MDA demonstrates the degree of severity of cellular damage (16). SOD and MDA are observed in the featured parameters efficacy of antioxidant therapy and the assessment of the presence of oxidative stress. SOD and GSH-Px activity is increased in the presence of oxidative stress (17). Steiling et al. (18) reported in their experimental study of wound healing in mice that SOD and GSH-Px levels are increased with oxidative stress in scar tissue. In addition, the increased expression of antioxidant enzymes during healing was evaluated for the purpose of adapting to the increased oxidative stress. In our study, SOD levels of the control group were lower than those of the study groups. A high SOD level was interpreted as a better elimination of free radicals by increasing enzymatic activity. SOD levels were higher in the topical group than in the parenteral and enteral groups; thus, GLN administered topically increased the SOD levels more. Marques et al. (19) reported in an experimental mucosal damage secondary to portal hypertension that GLN administration prevents the reduction in the SOD enzyme activity. In our study, high GSH-Px levels were interpreted as a better elimination of free radicals by increasing enzymatic activity in parallel observation of macroscopic and microscopic viewing.

Increased free radicals or decreased antioxidant defense mechanism leads to increased serum MDA levels. In our study, there was a significant difference between the control and enteral groups in terms of MDA levels $(p<0.02)$, whereas there was no increase in antioxidant enzyme compatible with increasing MDA level. These results can be interpreted as adjustment disorder of increased oxidative stress.

To evaluate wound healing, one of the most commonly used methods is measuring collagen levels. Generally, the determination of HYP level, which is abundant in collagen structure and less in the structure of other proteins, to identify the quantity of collagen tissue is the most commonly used method (20). In our study, tissue integrity was protected on the best level in the parenteral group that was not allowed for re-epithelialization.

\section{Study Limitations}

The limitation of the present study was the small number of samples that would consequently lead to partial inconclusive results. Further studies using larger sample size are suggested to obtain more precise results in the future.

\section{CONCLUSION}

A positive effect of GLN administration was observed in the treatment of traumatic oral mucosal lesions. It was considered that GLN administration via the topical or enteral route may present an alternative on traumatic oral mucosal lesions. However, GLN administration via the parenteral route had better results than that via topical and enteral routes.

Ethics Committee Approval: Ethics committee approval was received for this experimental study from the Animal Experiments Local Ethics Committee (Date: 30.01.2012, Protocol no: 2012-07) and conducted at the Animal Experiments Laboratory of Cerrahpaşa School of Medicine.

Informed Consent: N/A
Peer-review: Externally peer-reviewed.

Author Contributions: Concept - S.A., A.P.S.B.; Design - S.A., A.P.S.B.; Supervision - S.A., A.P.S.B., E.K.; Resources - S.A., A.P.S.B., G.G.; Data Collection and/or Processing - S.A., D.D.E., Ö.A.; Analysis and/or Interpretation - S.A., A.P.S.B.; Literature Search - S.A., E.K., Ö.A.; Writing Manuscript - S.A., A.P.S.B., G.G.; Critical Review - S.A., A.P.S.B., G.G.

Conflict of Interest: The authors have no conflict of interest to declare.

Financial Disclosure: This work was supported by Scientific Research Projects Coordination Unit of Istanbul University (Project number: 23763).

Acknowledgment: Thanks to M. D. Rovnat Babazade, M. D. Cem Sayilgan and Prof. Meltem Ercan for their contributions on analyzing and revising of manuscript.

\section{REFERENCES}

1. Köroğlu G. Hemşirelerin kemoterapiye bağlı gelişen oral mukozite ilişkin bilgilerin saptanması. Gazi Üniversitesi, Sağlık Bilimleri Enstitüsü, Ankara. Yüksek Lisans Tezi, 2007.

2. Naidu MU, Ramana GV, Rani PU, Mohan IK, Suman A, Roy P. Chemotherapy-induced and/or radiation therapy-induced oral mucositis--complicating the treatment of cancer. Neoplasia 2004; 6: 423-31. [CrossRef]

3. Ohtani M, Kawada S, Seki T, Okamoto Y. Amino acid and vitamin supplementation improved health conditions in elderly participants. J Clin Biochem Nutr 2012; 50: 162-8. [CrossRef]

4. Rubio IT, Cao Y, Hutchins LF, Westbrook KC, Klimberg VS. Effect of glutamine on methotrexate efficacy and toxicity. Ann Surg 1998; 227: 778-80. [CrossRef]

5. Shafer W, Hine M, levy B. A textbook of oral pathology. 4th ed. Philadelphia: Saunders; 1983. p. 594.

6. Klimberg VS, Salloum RM, Kasper M, Plumley DA, Dolson DJ, Hautamaki $D$, et al. Oral glutamine accelerates healing of the small intestine and improves outcome after whole abdominal radiation. Arch Surg 1990; 25: 1040-5. [CrossRef]

7. Li J, Chen J, Kirsner R. Pathophysiology of acute wound healing. Clin Dermatol 2007; 25: 9-18. [CrossRef]

8. Mutsaers SE, Bishop JE, McGrouther G, Laurent GJ. Mechanisms of tissue repair: from wound healing to fibrosis. Int J Biochem Cell Biol 1997; 29: 5-17. [CrossRef]

9. L-Glutamine. Altern Med Rev 2001; 6: 406-10.

10. Hall JC, Heel K, McCauley R. Glutamine. Br J Surg 1996; 83: 305. [CrossRef]

11. Ersin S, Tuncyurek P, Esassolak M, Alkanat M, Buke C, Yilmaz M, et al. The prophylactic and therapeutic effects of glutamine and arginineenriched diets on radiation-induced enteritis in rats. J Surg Res 2000; 89: 121-5. [CrossRef]

12. Li J, Langkamp-Henken B, Suzuki K, Stahlgren LH. Glutamine prevents parenteral nutrition- induced increases in intestinal permeability. JPEN 1994; 18: 303-7. [CrossRef]

13. Savarese DM, Savy G, Vahdat L, Wischmeyer PE, Corey B. Prevention of chemotherapy and radiation toxicity with glutamine. Cancer Treat Rev 2003; 29: 501-13. [CrossRef]

14. San-Miguel B, Crespo I, Kretzmann NA, Mauriz JL, Marroni N, Tuñón $\mathrm{MJ}$, et al. Glutamine prevents fibrosis development in rats with colitis induced by 2, 4, 6-Trinitrobenzene Sulfonic Acid. J Nutr 2010; 140: 1065-71. [CrossRef]

15. Serarslan G, Altug ME, Kontas T. Effect of caffeic acid phenethyl ester on plasma lipid peroxidation, antioxidant status and nitric oxide levels in incisional wound model. Türkderm 2007; 41: 11-4.

16. Eris $\mathrm{O}$, Cankayali I, Sezer E, et al. The effect of N-Acetylcysteine on oxidative stress in induced hemorrhagic shock model in rats. J Turk Anaesth Int Care 2009; 37: 208-216.

17. Matés JM. Effects of antioxidant enzymes in the molecular control of reactive oxygen species toxicology. Toxicology 2000; 153: 83-104. [CrossRef] 
18. Steiling H, Munz B, Werner S, Brauchle M. Different types of ROSscavenging enzymes are expressed during cutaneous wound repair. Exp Cell Res 1999; 247: 484-94. [CrossRef]

19. Marques C, Mauriz JL, Simonetto D, Marroni CA, Tuñon MJ, González-Gallego J, et al. Glutamine prevents gastric oxidative stress in an animal model of portal hypertension gastropathy. Ann Hepatol 2011; 10: 531-9.

20. Hendriks T, Mastboom WJ. Healing of experimental intestinal anastomoses. parameters for repair. Dis Colon Rectum 1990; 33: 891-901. [CrossRef] 